\title{
Viewpoint
}

\section{Comment to M Reynolds}

Journal of the Operational Research Society (2003) 54, 665. doi:10.1057/palgrave.jors.2601532

In a recent JORS viewpoint, $M$ Reynolds stated that there are 'frequent assertions amongst systems practitioners that Habermas himself no longer finds his earlier work defensible'. ${ }^{1}$ Four papers are cited in support of this statement. Number 6 is Clarke and Lehaney. ${ }^{2}$ We do not believe that there is any statement made by us anywhere in this paper that lends itself to offering the view ascribed to us by Reynolds. We suspect that Reynolds has either made a genuine error or that he has misinterpreted. We would be delighted to know where in our paper we provide any evidence to suggest that we hold the view ascribed to us by Reynolds. We recognise that interpretations may vary and we would be happy to be more considered in our choice of phrasing for the future if we have given a false impression.

\section{References}

1 Reynolds M (2002). In defence of knowledge constitutive interests. A comment on 'What is this thing called CST' (Midgley, 1996). J Opl Res Soc 53: 1162-1173.

2 Clarke S and Lehaney B (1999). Organisational intervention and the problems of coercion. Systemist 21: 40-52.

University of Coventry

B Lehaney

University of Luton

S Clarke

\section{Reply to B Lehaney and S Clarke}

Journal of the Operational Research Society (2003) 54, 665. doi:10.1057/palgrave.jors. 2601533

The reference to Clarke and Lehaney ${ }^{1}$ as one of the four sources supporting my claim that some systems practitioners state that 'Habermas himself no longer finds his earlier work defensible, ${ }^{2}$ is erroneous. I apologise sincerely to Steve and Brian for any discomfort and inconvenience caused by this error.

\section{References}

1 Clarke S and Lehaney B (1999). Organisational intervention and the problems of coercion. Systemist 21: 40-52.

2 Reynolds M (2002). In defence of knowledge constitutive interests. A comment on 'What is this thing called CST' (Midgley, 1996). J Opl Res Soc 53: 1162-1173.

The Open University

M Reynolds 